\title{
Steering Direction for a Powered-Wheelchair Using the Analytical Hierarchy Process
}

\author{
Malik Haddad \\ School of Mechanical and Design Engineering \\ University of Portsmouth \\ Portsmouth, UK \\ Martin Langner \\ Chailey Heritage Foundation / Engineering \\ Chailey Heritage Foundation \\ Chailey, UK \\ Giles Tewkesbury \\ School of Mechanical and Design Engineering \\ University of Portsmouth \\ Portsmouth, UK
}

\author{
David Sanders \\ School of Mechanical and Design Engineering \\ University of Portsmouth \\ Portsmouth, UK \\ Favour Ikwan \\ School of Mechanical and Design Engineering \\ University of Portsmouth \\ Portsmouth, UK \\ Alexander Gegov \\ School of Computing \\ University of Portsmouth \\ Portsmouth, UK
}

\begin{abstract}
For the first time, the Analytical Hierarchy Process (AHP) is employed to recommend a steering course for a powered-wheelchair. A safe route for a wheelchair is proposed by the decision-making system that tends to evade obstacles. Two ultrasonic transceivers are mounted onto a wheelchair. The resulting route is a blend between a provided direction from a user's joystick and a proposed direction from the decision making system that steers a powered-wheelchair to safely avoid obstacles in the way of the wheelchair. The procedure assists a disabled user to steer their wheelchair by choosing a direction that is a compromise between a direction suggested by the sensors and a direction requested by the driver. Sensitivity analysis explores directions amid uncertainty and risk. An appropriate direction is chosen but a human driver can over-ride the decision if necessary.
\end{abstract}

Keywords-Analytical Hierarchy Process; AHP; wheelchair; direction; steer; disabled;

\section{INTRODUCTION}

A Multi Criteria Decision Making (MCDM) structure is presented that assists with the control of a powered-wheelchair. Ultrasonics is employed to deliver information about the environment surrounding a wheelchair. The new system then assists disabled drivers to evade obstructions. A driver provides a preferred bearing and sensors are used to generate an alternative bearing. Intelligent mixing of the two produces a new bearing. Many researchers presented novel approaches to navigate powered wheelchairs: Neural Networks [1], Expert Systems [2-7], Cloud-based Systems [8], Machine Learning [9], Task programming [10] and Intelligent computers and sensors [11] in that way, disabled drivers are assisted and supported.
Powered-wheelchair driving and steering has been considered [12-17]. Methods have usually been local, without global improvement. Ways of avoiding obstacles have been investigated [18] that used sensors to give local information [19].

The use of MCDM with sensor data is presented. It can effectively drive the motors connected to the driving wheels of a powered wheelchair. The arrangement rapidly responds to obstacles ahead and tends to turn in the direction of a bearing indicated by a human driver while avoiding any obstacles.

A best compromise route is delivered that avoids collision. Direction and speed are controlled using a joystick and then a MCDM system adjusts the control if needed. The desires of a driver are traded off against distance to any detected obstacles. The new systems presented here were simulated before being tested using a wheelchair fitted with ultrasonic sensors.

The wheelchair had $2 \mathrm{x}$ outsized driving wheels attached on a common axis with two trailing casters. Orientation and movement were achieved by freely driving each outsized driving wheel. To accomplish this, each outsized wheel had its own coupled motor. Each motor was used to individually drive each outsized driving wheel. A driver was able to steer their chair by varying electrical current to the two motors.

Many researchers presented sensor systems that could help to avoid an obstacle [20] infrared [21], ultrasonics [22] and structured lighting [23]. Global systems behaved clumsily inside buildings [24] but local systems have proved to be more successful, including: ultrasonics [25-28], gyroscopes, odometers or tilt sensors. Ultrasonics was used because the sensors were simple, low cost and robust [28]. 
The sensors considered were like those described in [29]. They were mounted under the footrests of the wheelchair [30]. Range to obstacles was calculated by measuring time for pulses to be reflected back from objects [30]. If nothing was detected then detection ranges could be increased by increasing the length of the ultrasonic pulses until something was detected.

The area ahead was divided into a left-hand and a righthand side. A matrix could then be over-laid onto them. The matrix had three elements: VERY CLOSE, CLOSE and FAR-OFF. Transceiver beams over-lapped so that a center column in the matrix represented both left and right sensors detecting an obstacle. Any object ahead of the wheelchair was categorized as either VERY CLOSE, CLOSE or FAR-OFF.

Section II describes MCDM. Then Section III explains testing undertaken and presents some results. A short discussion is included in Section IV and some conclusions are presented in Section V.

\section{MCDM AND AHP}

MCDM is applied to evaluate alternatives to choose an appropriate bearing for the wheelchair with respect to criteria that occasionally disagreed [31]. MCDM help to solve realworld contradictory problems with multiple criteria that need to be considered, and they produce a suitable resolution even when presented with several possible solutions in circumstances that can be risky, uncertain or fuzzy [32 \& 33]. This is the first time this type of method has been applied to a powered-wheelchair application.

The Analytical Hierarchy Process (AHP) method was a popular MCDM method based on applying pairwise comparisons amongst options with respect to each criterion and then methodically delivering an overall total for each alternative with respect to all criteria. Criteria weights signified their relative importance. According to Saaty [34] AHP used the eigenvalue method, where a consistent matrix with known priorities pi was constructed and a comparison of alternatives $i$ and $\mathrm{j}$ is given by $\mathrm{pi} / \mathrm{pj}$, the comparison matrix was multiplied by the priority vector $\mathrm{p} \rightarrow$ then the result would be:

$$
\mathrm{A} \cdot \mathrm{Q}=\mathrm{n} \cdot \mathrm{Q}
$$

Where: $\mathrm{Q}=$ Vector of priorities; $\mathrm{n}=$ dimension of the matrix; $\mathrm{A}=$ comparison matrix.

Ishizaka and Labib [35] suggested $7 \mathrm{x}$ stages for decision making processes that use AHP:

- Identify alternatives, criteria and goals (that is "Problem Modelling").

- Pairwise Comparisons applied to every level in a hierarchy.

- AHP could consider qualitative and quantitative alternatives and criteria using a scale of preference consisting of $9 \times$ points ("A Judgments Scale").

- $\quad$ Priorities Calculation, using an eigenvalue technique.

- Consistency Analysis.
- Summation of local scores with respect to all criteria to evaluate the global scores of each alternative using:

$$
\mathrm{P}_{\mathrm{i}}=\sum_{\mathrm{j}} \mathrm{W}_{\mathrm{j}} \cdot \mathrm{l}_{\mathrm{ij}}
$$

Where: $\mathrm{P}_{\mathrm{i}}=$ global score of the alternative $\mathrm{i} ; \mathrm{W}_{\mathrm{j}}=$ weight of the criterion $\mathrm{j}$; $\mathrm{l}_{\mathrm{ij}}$ : local score.

- Sensitivity analysis.

AHP could aid decision makers in reaching suitable decisions that matched their aims as well as their understanding of problems. The next Section describe the application.

\section{TESTING}

The new system inputs were: (Dc).

Distance to an obstruction from the middle of the chair

Distance to an obstruction from the left side of the chair (D1). (Dr).

Distance to an obstruction from the right side of the chair

If nothing was detected then the safe range was fixed at one. Three situations are described as cases of a poweredwheelchair driving around in a setting having a few packing cases as obstructions.

- Case 1: Nothing perceived (Location A in Fig. 1).

- Case 2: Obstruction spotted on the right (B in Fig. 1).

- Case 3: Obstruction spotted on the left (C in Fig. 1).

Three options were judged: Move-Forward, Move-Right and Move-Left. Each alternative had a score derived and these are shown in Table I as a "decision matrix".

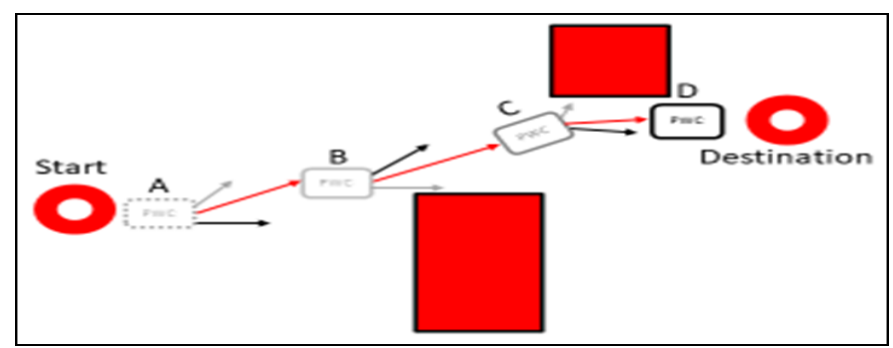

Figure 1. Powered-wheelchair driving through a setting containing some cardboard packages as obstacles

TABLE I. POWERED-WHEELCHAIR DECISION MATRIX

\begin{tabular}{|l|l|l|l|}
\hline \multirow{2}{*}{ Alternatives } & \multicolumn{3}{|c|}{ Criteria } \\
\cline { 2 - 4 } & \multicolumn{1}{|c|}{$\boldsymbol{D}_{\boldsymbol{l}}$} & \multicolumn{1}{c|}{$\boldsymbol{D}_{\boldsymbol{c}}$} & \multicolumn{1}{c|}{$\boldsymbol{D}_{\boldsymbol{r}}$} \\
\hline$\left(\mathrm{A}_{1}\right)$ Go left & 0.5 & 0.25 & 0.167 \\
\hline$\left(\mathrm{A}_{2}\right)$ Go forward & 0.333 & 0.5 & 0.333 \\
\hline$\left(\mathrm{A}_{3}\right)$ Go right & .167 & 0.25 & 0.5 \\
\hline
\end{tabular}

The area in front of a wheelchair was divided to left and right. If no obstacle was detected $D_{1}, D_{c}$ and $D_{r}$ were set to 1 . If 
the right transducer detected an obstacle and the left transduce did not detect anything then $D_{1}$ was set to 1 and $D_{c}$ and $D_{r}$ were calculated using (3) and (4).

$$
\begin{aligned}
& \mathrm{D}_{\mathrm{c}}=\mathrm{D} \cos (\phi) \\
& \mathrm{D}_{\mathrm{r}}=\mathrm{D} \sin (\phi)
\end{aligned}
$$

Where: $\mathrm{D}=$ Distance between the wheelchair and the obstacle; $\phi=$ Angle at which the obstacle was detected.

If the left transducer detected an obstacle and the right transduce did not detect anything then $D_{r}$ was set to 1 and $D_{c}$ and $D_{1}$ were calculated using (3) and (5).

$$
\mathrm{D}_{1}=\mathrm{D} \sin (\phi)
$$

Where: $\mathrm{D}=$ Distance between the wheelchair and the obstacle; $\phi=$ Angle at which the obstacle was detected.

Case 1 Location A in Fig. 1): The powered-wheelchair started moving, nothing was detected by the sensors, distances were all fixed as FAR-OFF. AHP was employed with three alternatives and three criteria being assessed. The three criteria weights were fixed as one. AHP produced a ranking of alternatives: $A_{2}>\left(A_{1}=A_{3}\right)$. Overall scores for alternatives were: $\mathrm{A}_{1}=0.306, \mathrm{~A}_{2}=0.389$ and $\mathrm{A}_{3}=0.306$. The overall scores of the alternatives were represented as vector magnitudes as shown in Fig. 2 and the overall direction suggested by AHP was calculated using vector algebra and shown as a heavy black line in Fig. 3. That is to drive on a bearing specified by the driver of the powered-wheelchair.

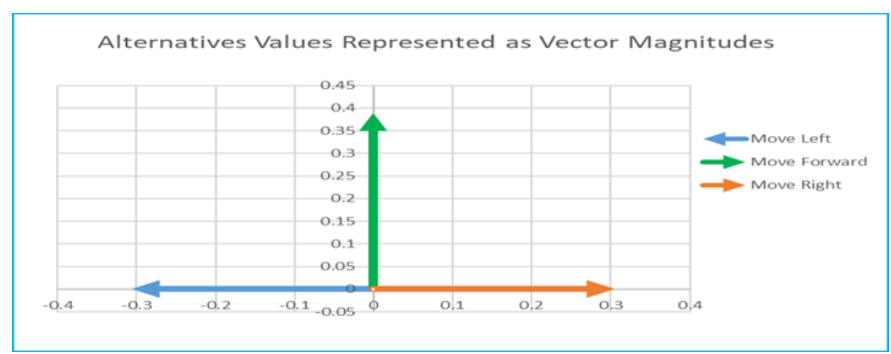

Figure 2. Overall scores of alternatives represented as vector magnitudes, Case 1: no obstacle was detected

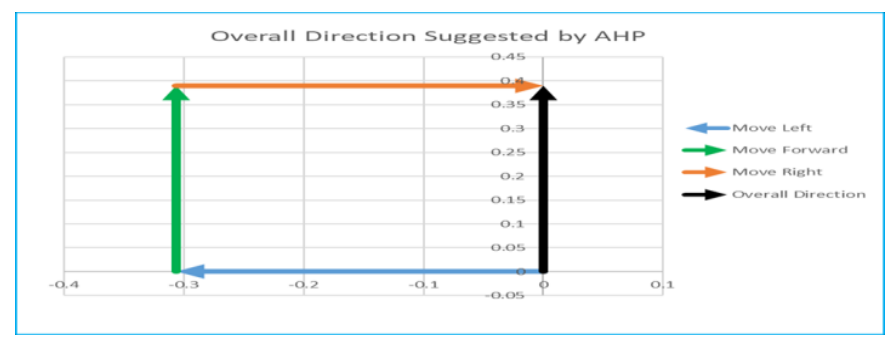

Figure 3. Overall direction suggested by AHP for case 1

The stability of the result was assessed using sensitivity analysis with criteria weights. The lowest changes required to switch the result was determined. Table II shows the results. $\mathrm{N} / \mathrm{F}$ represented a non-feasible denomination where $\pm 100 \%$ modification to a criterion weighting didn't change the result.
TABLE II. Minimum Percentage Change NeEded In CRITERIA WeIGHTS to SWITCH THE OUTCOME OF AHP, CASE 1, NothING DETECTED

\begin{tabular}{|l|l|}
\hline \multicolumn{1}{|c|}{$\begin{array}{c}\text { Criterion } \\
\text { name }\end{array}$} & \multicolumn{1}{|c|}{ Minimum percentage change } \\
\hline$D_{\mathrm{l}}$ & $\pm 0.1 \%$ \\
\hline $\mathrm{D}_{\mathrm{c}}$ & $\mathrm{N} / \mathrm{F}$ \\
\hline $\mathrm{D}_{\mathrm{r}}$ & $\pm 0.1 \%$ \\
\hline
\end{tabular}

Sensitivity analysis revealed that a $0.1 \%$ change in $D_{1}$ or $D_{r}$ would change the bearing for the powered-wheelchair. $0.1 \%$ rise in $D_{1}$ or $0.1 \%$ reduction in $D_{r}$ made the wheelchair drive ahead but with a small bearing to the left, a $0.1 \%$ decrease in $D_{1}$ or a $0.1 \%$ increase in $D_{r}$ made the wheelchair drive ahead but with a small bearing to the right.

Case 2 (location B in Fig. 1): The powered-wheelchair drove forwards, and an object was detected on the right side as shown in Fig. 1. The obstacle was 0.447 meters away at an angle of $63.49^{\circ}$ as shown in Fig. 4.

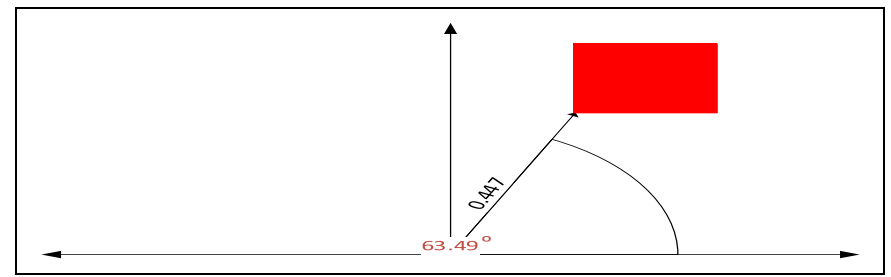

Figure 4. Object detected to the right

Since the left transducer did not sense any obstacles $D_{1}$ was set to $1 . D_{c}$ and $D_{r}$ were calculated using (3) and (4).

AHP was used were three criteria and three alternatives were assessed. AHP produced a ranking of alternatives: $A_{1}>$ $A_{2}>A_{3}$ with an overall score of alternatives: $A_{1}=0.396$, $\mathrm{A}_{2}=0.375$ and $\mathrm{A}_{3}=0.229$. The overall scores of the alternatives were represented as vector magnitudes as shown in Fig. 5 and the overall direction suggested by AHP was calculated using vector algebra and shown as a heavy black line in Fig. 6.

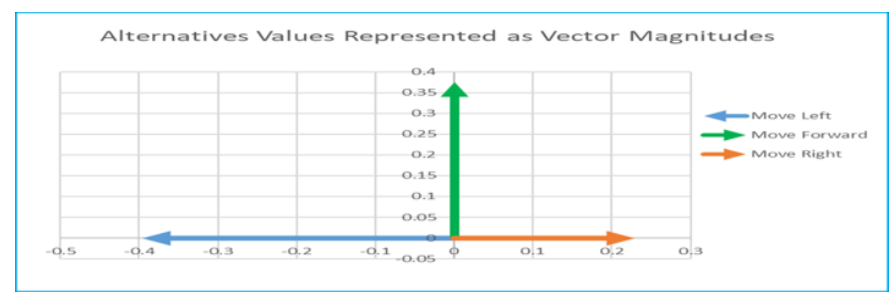

Figure 5. Overall scores of alternatives represented as vector magnitudes, Case 2: obstacle detected to the right

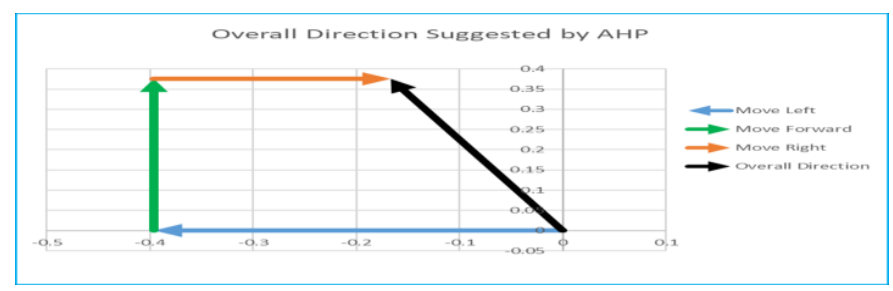

Figure 6. Overall direction suggested by AHP for case 2 
The stability of the result was assessed using sensitivity analysis with criteria weights. The lowest changes required to switch the result was determined. Results are shown in Table III.

Sensitivity analysis revealed the consequence of making the smallest change in $D_{r}, D_{c}$ and $D_{l}$ on the recommended wheelchair bearing. An $8.960 \%$ reduction in $\mathrm{D}_{1}$, a $24 \%$ rise in $\mathrm{D}_{\mathrm{c}}$ or an $81.667 \%$ rise in $\mathrm{D}_{\mathrm{r}}$ made the chair drive forward and left on a bearing of $134^{\circ}$.

TABLE III. MINIMUM CHANGE NEEDED IN CRITERIA WEIGHTS TO Switch the Result of AHP, CAse 2, AN OBJeCt Detected to the Right

\begin{tabular}{|l|l|}
\hline \multicolumn{1}{|c|}{ Criterion name } & \multicolumn{1}{|c|}{ Minimum percentage change } \\
\hline$D_{1}$ & $-8.960 \%$ \\
\hline$D_{c}$ & $24 \%$ \\
\hline$D_{r}$ & $81.667 \%$ \\
\hline
\end{tabular}

Case 3 (Location $\mathrm{C}$ in Fig.7): The powered-wheelchair drove forwards, and something was sensed to the left as shown in Fig. 7. The obstacle was 0.25 meters away at an angle of $36^{\circ}$ as shown in Fig. 8.

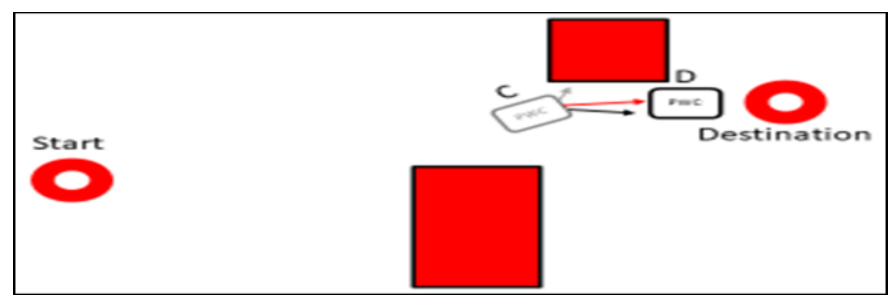

Figure 7. Overall direction suggested by AHP for case

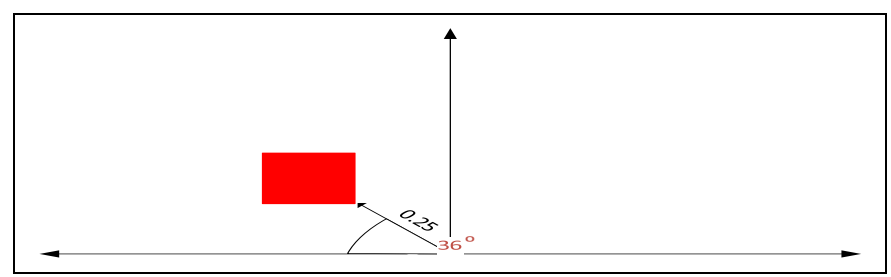

Figure 8. Object detected to the left

Since the right transducer did not sense any objects $D_{r}$ was set to $1, D_{c}$ and $D_{1}$ were calculated using (3) and (5).

AHP was used and three alternatives and three criteria were assessed. AHP generated a ranking: $A_{3}>A_{2}>A_{1}$ with an overall score of alternatives: $\mathrm{A}_{1}=0.226, \mathrm{~A}_{2}=0.351$ and $\mathrm{A}_{3}=0.423$. The overall scores of the alternatives were represented as vector magnitudes as shown in Fig. 9 and the overall direction suggested by AHP was calculated using vector algebra and shown as a heavy black line in Fig. 10.

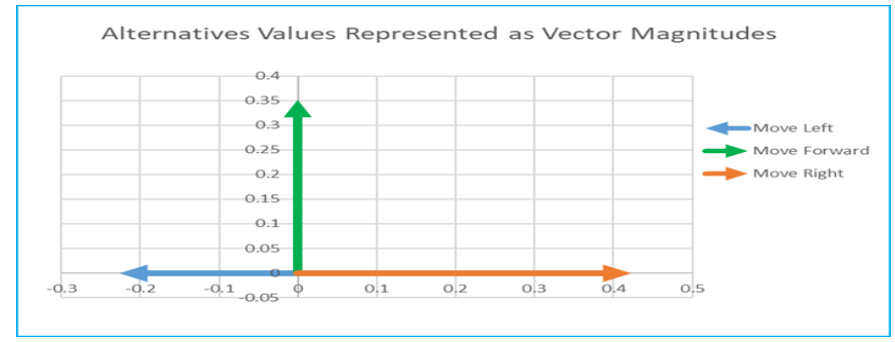

Figure 9. Overall scores of alternatives represented as vector magnitudes, case 3: object detected on the left

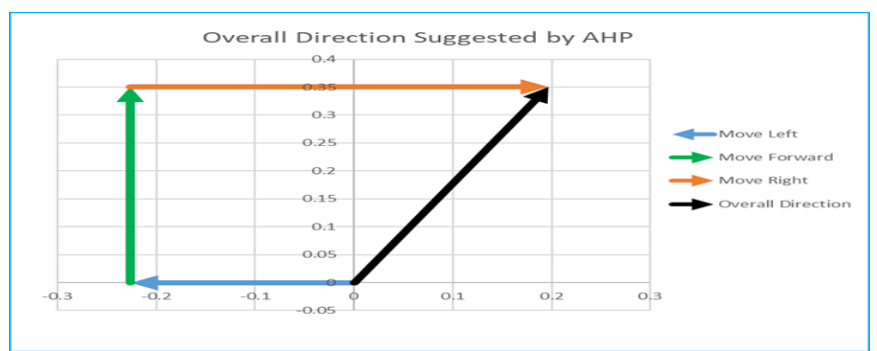

Figure 10. Overall direction suggested by AHP for case 3

The stability of the result was assessed using sensitivity analysis with criteria weights. The lowest changes required to switch the result was determined and Table IV shows the results. N/F represented a non-feasible result when $\pm 100 \%$ modification didn't change the result.

TABle IV. Minimum Percentage Change NeEded in CRiteria Weights to Change Result of AHP, CASE 3, One ObSTACLE WaS SPOTTED ON THE LEFT

\begin{tabular}{|l|l|}
\hline \multicolumn{1}{|c|}{ Criterion name } & \multicolumn{1}{|c|}{ Minimum percentage change } \\
\hline$D_{1}$ & $\mathrm{~N} / \mathrm{F}$ \\
\hline$D_{\mathrm{c}}$ & $\mathrm{N} / \mathrm{F}$ \\
\hline$D_{\mathrm{r}}$ & $26.721 \%$ \\
\hline
\end{tabular}

Sensitivity analysis revealed the consequence of making the smallest percentage change in $D_{r}, D_{c}$ and $D_{1}$ on the proposed bearing. A $171.333 \%$ rise in $D_{l}$, a $185.321 \%$ rise in $D_{c}$ or a $26.721 \%$ rise in $\mathrm{D}_{\mathrm{r}}$ made the chair drive right and forward on a bearing of $46^{\circ}$.

\section{DISCUSSION}

The system successfully blended information from a user joystick with information form sensors. Powered-wheelchair drivers controlled their chairs using joysticks and sensors handled obstacle avoidance. Sensors systems guaranteed the chair was safe. The output from the controller was a summation of the output from the decision-making system and the weighted desire of the user. Ccomd (the resulting control command) was evaluated using (6):

$$
\mathrm{C}_{\text {comd }}=\left(\mathrm{G}_{\mathrm{h}}|\mathrm{J}|+\mathrm{k}_{\mathrm{t}} \mathrm{C}_{\text {sens }}\right)
$$


Where $G_{h}|\mathrm{~J}|$ is the joystick command, $\mathrm{C}_{\text {sens }}$ is the decisionmaking output and $\mathrm{k}_{\mathrm{t}}$ was an increasing variable (increasing over time) so the user can override the decision-making output.

Fig.11 shows the resultant direction when mixing the output suggested by AHP when nothing was being sensed and the joystick was being kept left. The line shown in black was the MCDM output, the line shown in grey was the joystick output and the line shown in red was the resulting actual direction and speed.

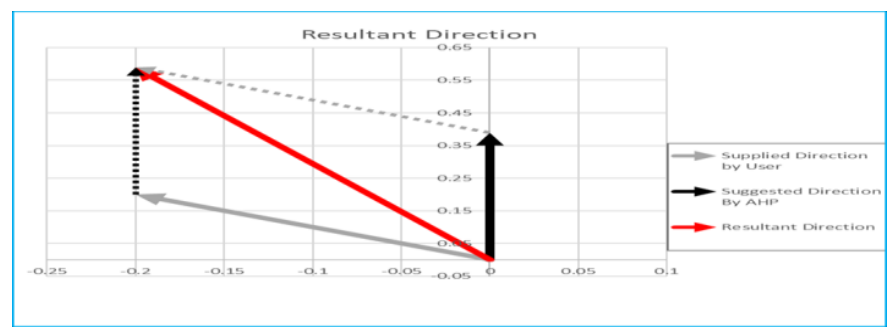

Figure 11. Direction of the Wheelchair after mixing AHP output without anything sensed and the joystick held left

Fig. 12 shows the resultant wheelchair bearing when something was sensed on the right, and the joystick was pushed forward. Fig. 13 shows the resultant wheelchair bearing when something was sensed on the left, and the joystick was pushed right.

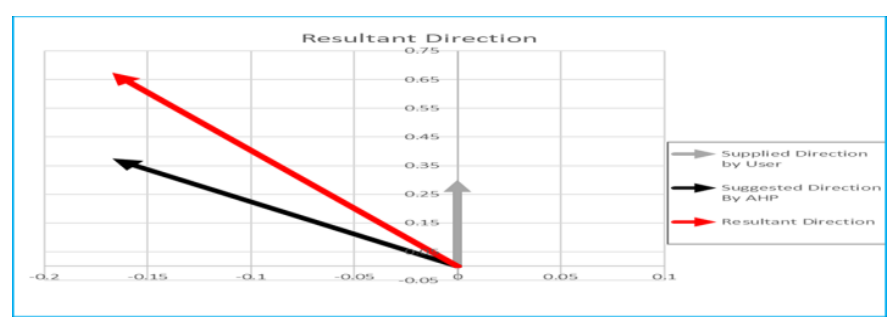

Figure 12. Direction of the Wheelchair after mixing: AHP output with an obstacle detected to the right, and joystick was pushed forward

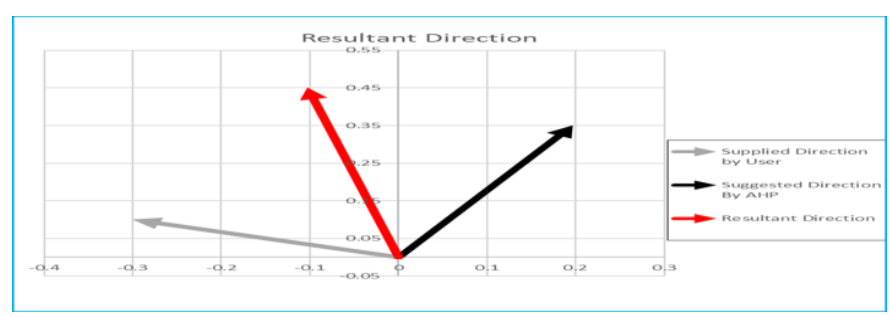

Figure 13. Direction of the Wheelchair after mixing: AHP output with an obstacle detected to the left and joystick was pushed to the right.

\section{CONCLUSIONS}

The work explained in this paper successfully used AHP (a MCDM method) to avoid collisions. Straightforward, effective and safe outcomes were achieved. Wheelchair drivers were aided with driving their wheelchairs as obstacles were rapidly sensed and wheelchairs were driven safely round them.

The work could bring some autonomy and reduce the need for helpers.
Rules were hard-coded and could not learn and that could be seen as a limitation. The authors are now investigating ways for the system to understand additional situations by merging dissimilar AI techniques [2, 29, $36 \& 37]$. The notion will be that various AI techniques can be applied to their best advantage.

MCDM could not consider all situations so neuro, reinforcement or neuro-fuzzy learning could deliver efficient outcomes. These algorithms will be explored.

Systems attempted to avoid obstructions but if a driver determinedly indicated they wanted to drive towards something then the driver could overrule the decision-making system. The system could be overruled by holding a joystick still so that the user would eventually overrule the system.

The chair drove as desired by the driver if nothing was sensed.

The authors are currently applying the AHP and Preference Ranking Organization MEthod for Enrichment of Evaluation (PROMETHEE) method to other problems. A framework for the intelligent selection of MCDM methods has been created [38].

The authors are applying different MCDM methods to different types of problems [39-41]. Future work will consider a bigger set of alternatives to consider $360^{\circ}$ around the chair. Uncertainty will be denoted using probability functions, fuzzy set theory and percentages.

Results show that the decision making worked suitably. Systems will be clinically trialed at Chailey Heritage as part of an ERSPC funded project [42]. Research is now examining path modification [43], force sensing [44] and contrasting accomplishments both with the sensors and without sensors [45].

\section{ACKNOWLEDGMENT}

This research was supported by an EPSRC EP/S005927/1 project titled "Using artificial intelligence to share control of a powered-wheelchair between a wheelchair user and an intelligent sensor system". Investigators: Sanders, DA and Gegov, AE. Senior Researcher Haddad MJM.

\section{REFERENCES}

[1] D. R. Parhi, and M. K. Singh, "Rule-based hybrid neural network for navigation of a wheelchair,” P I Mech Eng B-J Eng, vol. 224, pp.11103 $-1117,2009$.

[2] D. A. Sanders, A. Gegov, D. Ndzi, "Knowledge-based expert system using a set of rules to assist a tele-operated mobile robot," Studies in Computational Intelligence, 751, Springer, 2018, pp. 371-392, 2018.

[3] D. A. Sanders, et al. "A Rule-based Expert System to decide on direction and speed of a powered-wheelchair," IEEE Proceedings of the SAI Conference on IntelliSys. London, U.K., pp. 426 - 433, 2018.

[4] D. Sanders, M. Langner, N. Bausch, Y. Huang, S. A. Khaustov, and S. Simandjuntak, "Improving human-machine interaction for a poweredwheelchair driver by using variable-switches and sensors that reduce wheelchair-veer," Intelligent Systems and Applications. Adv. Intell. Syst. Comput, vol. 1038, Springer, pp. 1173-1191, 2019.

[5] D. Sanders, O. M. Okonor, M. Langner, S. M. Hassan, S. A. Khaustov, and P. O. Omoarebun, "Using a simple expert system to assist a 
powered-wheelchair user," Intelligent Systems and Applications. Adv. Intell. Syst. Comput, vol. 1037, Springer, pp. 662-379, 2019.

[6] D. Sanders, A. Gegov, M. Haddad, F. Ikwan, D. Wiltshire, and Y. C. Tan, "A rule-based expert system to decide on direction and speed of a powered-wheelchair,” Adv. Intell. Syst. Comput, vol. 868, Springer, pp. 822-838, 2019.

[7] M. Haddad, D. Sanders, N. Bausch, G. Tewkesbury, A. Gegov, and M. Hassan Sayed, "Learning to make intelligent decisions using an Expert System for the intelligent selection of either PROMETHEE II or the Analytical Hierarchy Process," Adv. Intell. Syst. Comput, vol. 868, Springer, pp. 1303-1316, 2019.

[8] O. M. Okonor, A. Gegov, M. Adda, D. Sanders, M. Haddad, and G. Tewkesbury, "Intelligent approach to minimizing power consumption in a cloud-based system collecting sensor data and monitoring the status of powered-wheelchairs," Intelligent Systems and Applications. Adv. Intell. Syst. Comput, vol. 1037, Springer, pp. 694-710, 2019.

[9] N. Bausch, P. Shilling, D. Sanders, M. Haddad, O. M. Okonor, and G. Tewkesbury, "Indoor location and collision feedback for a poweredwheelchair system using machine learning," Adv. Intell. Syst. Comput, Vol. 1 pp. 721-739, 2019.

[10] G. Tewkesbury, D. Sanders, M. Haddad, N. Bausch, A. Gegov, and O.M. Okonor, "Task programming methodology for poweredwheelchairs,” Adv. Intell. Syst. Comput, Vol. 1 pp. 711-720, 2019.

[11] D. Sanders, G. Tewkesbury, H. Parchizadeh, J. J. Robertson, P. O. Omoarebun, and M. Malik, "Learning to drive with and without intelligent computer systems and sensors to assist," Adv. Intell. Syst. Comput, vol. 868, Springer, pp. 1171-1181, 2019.

[12] D. R. Parhi et al. "The stable and precise motion control for multiple wheelchairs", Appl. Soft Comput, vol. 9, no. 2, pp. 477 - 487, 2009.

[13] V. Nguyen et al. "Strategies for Human - Machine Interface in an Intelligent Wheelchair," 35th Annual Int Conf of IEEE-EMBC, Osaka, JAPAN. Book Series: IEEE Engineering in Medicine \& Biology Society, 2013, pp. 3638-3641.

[14] M. Haddad, D. Sanders, A. Gegov, A, M. Hassan Sayed, Y. Huang, and M. Al-Mosawi, "Combining multiple criteria decision making with vector manipulation to decide on the direction for a poweredwheelchair," Adv. Intell. Syst. Comput, vol. 1037, Springer, pp. 680693, 2019.

[15] M. Haddad, D. Sanders, G. Tewkesbury, A. Gegov, M. Hassan Sayed, and F. Ikwan, "Initial results from using Preference Ranking Organization METHods for Enrichment of Evaluations to help steer a powered-wheelchair," Adv. Intell. Syst. Comput, vol. 1037, Springer, pp. 648-661, 2019.

[16] D. Sanders, Q. Wang, N. Bausch, Y. Huang, S. A. Khaustov, and I. Popov, "A method to produce minimal real time geometric representations of moving obstacles, Adv. Intell. Syst. Comput, vol. 868, Springer, pp. 881-892, 2019

[17] D. Sanders, A. Gegov, G. Tewkesbury, and R. Khusainov, "Sharing driving between a vehicle driver and a sensor system using trust-factors to set control gains," Adv. Intell. Syst. Comput, vol. 868, Springer, pp. 1182-1195, 2019

[18] D. A. Sanders et al. "Results from investigating powered-wheelchair users learning to drive with varying levels of sensor support," in Proc SAI Intelligent System, London, U.K. 2017, pp. 241-245

[19] K. T. Song, and C. C. Chen, "Application of asymmetric mapping for wheelchair navigation using ultrasonic sensors," J. Intell. Wheelchair Syst., vol. 17, no. 3, pp. 243 - 264, 1996.

[20] D. Sanders, M. Langner, and G. Tewkesbury, "Improving wheelchairdriving using a sensor system to control wheelchair-veer and variableswitches as an alternative to digital-switches or joysticks," Ind Rob: An int' jnl, vol. 37, no. 2, pp.151-167, 2010.

[21] S. Lee, "Use of infrared light reflecting landmarks for localization," Ind Rob: An int' jnl, vol. 36, no. 2, pp. 138-145, 2009.

[22] D. Sanders, I. Stott, "A new prototype intelligent mobility system to assist powered-wheelchair users," Ind Rob, vol. 26, no. 6, pp. 466-475, 2009.

[23] J. Larsson, M. Broxvall, and A. Saffiotti, "Laser-based corridor detection for reactive Navigation," Ind Rob: An int' jnl, vol. 35, no. 1, pp. 69-79, 2008.
[24] V. Milanes, J. Naranjo, and C. Gonzalez, "Autonomous vehicle based in cooperative GPS and inertial systems,” Robotica, vol. 26, pp. 627-633, 2008

[25] D. A. Sanders, "Controlling the direction of walkie type forklifts and pallet jacks on sloping ground," Assem. Autom., vol. 28, no. 4, pp. 317 324, 2008.

[26] D. Sanders, "Recognizing shipbuilding parts using artificial neura networks and Fourier descriptors," P I Mech Eng B-J Eng, vol. 223, no. 3, pp. 337-342, 2009.

[27] Y. C. Chang, and Y. Yamamoto, "On-line path planning strategy integrated with collision and dead-lock avoidance schemes for wheeled wheelchair in indoor environments," Ind Rob: An int' jnl, vol. 35, no. 5 , pp. 421-434, 2008.

[28] D. Sanders, "Comparing speed to complete progressively more difficul mobile robot paths between human tele-operators and humans with sensor-systems to assist," Assem. Autom., vol. 29, no. 3, pp. 230-248 2009.

[29] D. A. Sanders, "Using self-reliance factors to decide how to share control between human powered-wheelchair drivers and ultrasonic sensors," IEEE Trans Neural Syst Rehabil Eng, vol. 25, no. 8, pp. 1221 $1229,2017$.

[30] D. Sanders, et al. "Tele-operator performance and their perception of system time lags when completing mobile robot tasks," Proc 9th Int Conf on Human Systems Interaction, 2016, pp. 236-242.

[31] A. Ishizaka, S. and Siraj, "Are multi-criteria decision-making tools useful? An experimental comparative study of three methods," EJOR, 264, 462-471, 2018.

[32] K. Raju, and D. Kumar, "Irrigation Planning using Genetic Algorithms," Water Resour Manag, vol. 18, pp. 163 - 176, 2004

[33] M. Haddad, D. Sanders, and N. Bausch, "Selecting a robust decision making method to evaluate employee performance," Int J Manag Decis Making, vol. 18, no. 4, pp. 333-351, 2019.

[34] T. L. Saaty, "Decision making with the analytic hierarchy process," Int J Serv Sci, vol. 1, no. 1, pp. 83-98, 2008.

[35] A. Ishizaka, and A. Labib, "Analytic hierarchy process and expert choice: Benefits and limitations," Or Insight, vol. 22, no. 4, pp. 201-220, 2009

[36] A. Gegov, N. Gobalakrishnan, and D. A. Sanders, "Rule base compression in fuzzy systems by filtration of non-monotonic rules," J Intell Fuzzy Syst, vol. 27, no. 4, pp. 2029-2043, 2014.

[37] D. A. Sanders et al. "Rule-based system to assist a tele-operator with driving a mobile robot," Lecture Notes in Networks and Systems, 16, Springer, pp. 599-615, 2018

[38] M. Haddad, and D. Sanders, "Visual representation of stability for three discrete Multi-Criteria Decision Making Methods," J Oper Res Soc, Submitted and Under Review.

[39] M. Haddad, D. Sanders, and G. Tewkesbury, "Selecting a discrete Multiple Criteria Decision Making method to decide on a corporate relocation," Arch Bus Res, vol. 7, no. 5, pp. 48-67, 2019.

[40] M. Haddad, and D. Sanders, "Selecting a best compromise direction for a powered-wheelchair using PROMETHEE," IEEE Trans Neural Syst Rehabil Eng, vol. 27, no. 2, pp. 228-235, 2019.

[41] D. Sanders, D. C. Robinson, M. Hassan Sayed, M. Haddad, A. Gegov, and N. Ahmed, "Making decisions about saving energy in compressed air systems using Ambient Intelligence and Artificial Intelligence," Adv. Intell. Syst. Comput, vol. 869, Springer, pp. 1229-1236, 2018.

[42] D. Sanders, and A. Gegov, "Using artificial intelligence to share contro of a powered-wheelchair between a wheelchair user and an intelligent sensor system," EPSRC Project 2019 - 2022, 2018.

[43] D. A. Sanders, "The modification of pre-planned manipulator paths to improve the gross motions associated with the pick and place task," Robotica, vol. 13, pp. 77-85, 1995.

[44] D. A. Sanders, "Viewpoint - Force sensing," Industrial Robot, vol. 34, p. 177, 2007.

[45] D. Sanders, "Comparing ability to complete simple tele-operated rescue or maintenance mobile-robot tasks with and without a sensor system,' Sensor Rev, vol. 30, no. 1, pp. 40-50, 2010. 